\title{
Mitigation-driven translocations: are we moving wildlife in the right direction?
}

\author{
Jennifer M Germano ${ }^{1,2^{*}}$, Kimberleigh J Field ${ }^{3}$, Richard A Griffiths ${ }^{4}$, Simon Clulow ${ }^{5}$, Jim Foster ${ }^{6}$, \\ Gemma Harding ${ }^{4}$, and Ronald R Swaisgood ${ }^{1}$
}

Despite rapid growth in the field of reintroduction biology, results from scientific research are often not applied to translocations initiated when human land-use change conflicts with the continued persistence of a species' population at a particular site. Such mitigation-driven translocations outnumber and receive more funding than science-based conservation translocations, yet the conservation benefit of the former is unclear. Because mitigation releases are economically motivated, outcomes may be less successful than those of releases designed to serve the biological needs of species. Translocation as a regulatory tool may be ill-suited for biologically mitigating environmental damage caused by development. Evidence suggests that many mitigation-driven translocations fail, although the application of scientific principles and best practices would probably improve the success rate. Lack of transparency and failure to document outcomes also hinder efforts to understand the scope of the problem. If mitigation-driven translocations are to continue as part of the growing billion-dollar ecological consulting industry, it is imperative that the scale and effects of these releases be reported and evaluated.

Front Ecol Environ 2015; 13(2): 100-105, doi:10.1890/140137 (published online 16 Jan 2015)

$T^{\prime}$ he use of translocations - the human-mediated, intentional movement of living organisms from one area to another as a wildlife management tool - has risen exponentially over the past few decades (Seddon et al. 2007; IUCN/SSC 2013). Indeed, numbers of translocations are predicted to increase even more rapidly if assisted colonization is adopted as a tool for climate-change mitigation (Hoegh-Guldberg et al. 2008; IUCN/SSC 2013). Although the field of reintroduction biology is moving steadily forward

\section{In a nutshell:}

- The number of mitigation translocations - the movement of animals out of the path of development projects - appears to be increasing rapidly and likely far exceeds the number of conservation-driven translocations

- Mitigation-driven translocations all too often fail to follow accepted scientific best practices and are poorly documented providing few opportunities to apply lessons learned and to improve the conservation efficacy of similar projects in the future

- A new approach to mitigation-driven translocations rejects "tit-for-tat" translocations as a way to mediate impacts at a development site and instead substitutes a more strategic allocation of resources in a scientifically responsible and conservation-relevant fashion

${ }^{1}$ Institute for Conservation Research, San Diego Zoo Global, Escondido, CA; ${ }^{2}$ Department of Conservation, Hamilton, New Zealand*(JGermano@doc.govt.nz); ${ }^{3}$ Desert Tortoise Recovery Office, US Fish and Wildlife Service, Reno, NV; ${ }^{4}$ Durrell Institute of Conservation and Ecology, School of Anthropology and Conservation, University of Kent, Kent, UK; ${ }^{5}$ School of Environmental and Life Sciences, University of Newcastle, Callaghan, Australia; ${ }^{6}$ Amphibian and Reptile Conservation, Witley Centre, Witley, UK through the application of scientific principles (Seddon et al. 2007), many wildlife translocations have evaded academic scrutiny and have not been subject to a common set of widely accepted standards. These translocations attempt to reduce animal mortality caused by human activities (eg development), by relocating individuals away from project sites. This motive for relocating animals is quite different from need-based strategies to augment or restore animal populations through conservation-driven translocations. While the motives may differ, the techniques used and scrutiny applied should be similar (IUCN/SSC 2013). Henceforth, we refer to translocations initiated to reduce animal deaths as a result of development activities as "mitigation-driven translocations" (Panel 1). Many countries have regulatory frameworks that cover such translocations. Legal requirements, driven in part by public perception and pressure, also provide the primary funding mechanism for such activities, requiring that developers relocate protected species from affected land. This raises the question of whether such animals are simply being spared a socially unacceptable death via bulldozer only to perish out of view at a release site (eg "phased destruction"; Jackson et al. 1983), or whether the translocations are a useful tool, wisely applied to minimize the effects of humans' actions on imperiled wildlife. We contend that mitigation-driven translocations, while well-financed, are often inappropriately executed, poorly documented, and unquestioningly used without regard to larger, more strategic conservation goals.

\section{Scope of the issue}

Mitigation-driven translocations have risen sharply over the past 10-15 years (Miller et al. 2014), perhaps more so 
than conservation-based releases, and are often generously funded. It is currently impossible to ascertain the level of investment in these activities, but the global ecological consultancy market has an estimated value of between US $\$ 1.6$ billion and US $\$ 4.8$ billion (Hill and Arnold 2012). Although translocations may represent only a small proportion of consultancy services, the amount spent on mitigation-driven translocations easily dwarfs that allocated to conservation-focused translocation programs carried out by government and nonprofit groups. In Australia, an estimated AU $\$ 14.14$ million (US\$11.85 million) has been spent on mitigation-based translocations for a single species of frog (green and golden bell frog Litoria aurea) over the past 15 years, as compared with an estimated AU\$3.29 million (US\$2.76 million) devoted to conser-

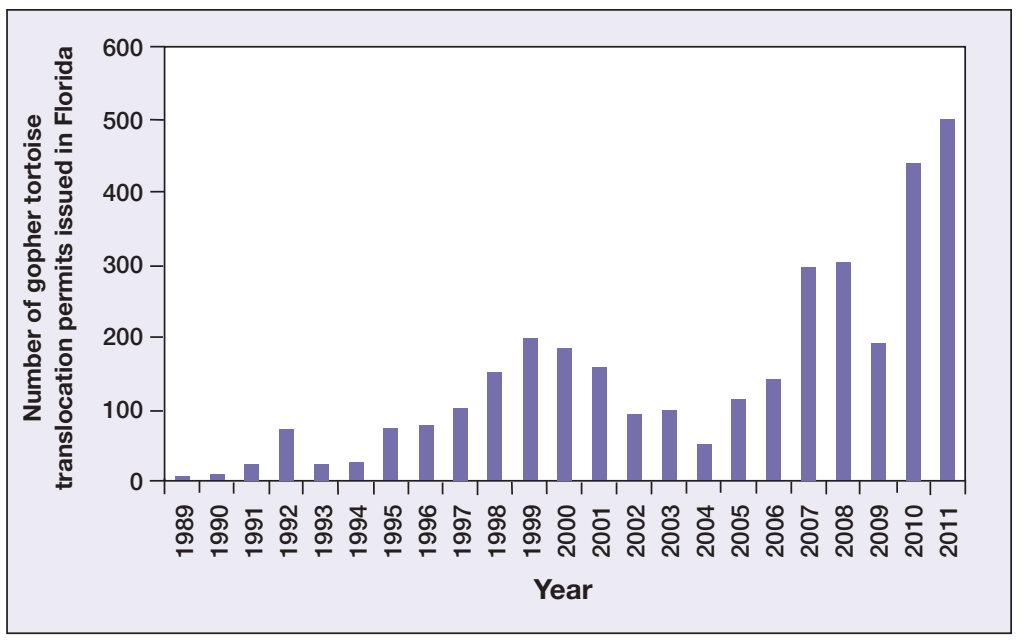

Figure 1. Gopher tortoise (Gopherus polyphemus) translocation permits issued in the US state of Florida (1989-2011). Data from Florida Fish and Wildlife Conservation Commission, courtesy of S Power and J Berish.

vation-based translocations for all other amphibian species combined during the same time period. In the UK, the cost of mitigating development-related impacts on great crested newts (Triturus cristatus) approaches $£ 100000-£ 200000$ (US\$157 000-US\$314 000) per project, an order of magnitude higher than the expenditure on other conservation actions for the same species (Lewis 2012). In the US, one solar energy project expected to spend US $\$ 22$ million on activities related to the translocation of Mojave desert tortoises (Gopherus agassizii) from the development site (Desmond 2012); fortunately, a monitoring plan was included in this project's approval process. In Brazil, purportedly vast monetary sums are dedicated to relocating animals from the sites of large hydroelectric projects; such actions are legally required but essentially undocumented (Teixeira et al. 2007).

The numbers of animals moved from project sites can be astounding. In one particular case, almost 24000 reptiles (290 adders [Vipera berus], 400 grass snakes [Natrix natrix],
17000 common lizards [Zootoca vivipara], and 6000 slow worms [Anguis fragilis]) as well as 300 water voles (Arvicola amphibius) and over 350 great crested newts ( $T$ cristatus) were relocated for a port development project in the UK (Leggett 2011; Williams 2011). In Australia, almost 20 000 tadpoles and more than 350 post-metamorphic green and golden bell frogs were translocated to five locations as part of a single mitigation-based translocation program (McFadden et al. 2008); there are many other examples at similar or greater scales taking place. Since 1989, more than 70000 individual gopher tortoises (Gopherus polyphe$m u s$ ), which are the focus of hundreds of mitigationdriven projects in the southeastern US, have been permitted for translocation in the state of Florida alone (Florida Fish and Wildlife Conservation Commission, unpublished data). The Florida Fish and Wildlife Conservation Commission, one of the few government agencies worldwide that is tracking wildlife translocations, has seen a marked increase in translocation permits issued for gopher tortoises during the past 5 years (Figure 1).

\section{Panel 1. What is a mitigation-driven translocation?}

We use the term "mitigation-driven" to characterize translocations that are implemented in response to legislation or governmental regulation, with the intent of reducing a development project's effects on animals or plants inhabiting the site. These translocations are therefore, by nature, reactions to immediate anthropogenic threats to species under governmental protection, such as those listed under the US Endangered Species Act. The regulatory intent is clearly to mitigate the population-level effects of the loss of individuals of the protected species and their habitat. However, we argue that the language and enforcement of these regulations often do not address this intended outcome effectively. The word mitigation is often used to describe an attempt to offset or balance out the unavoidable negative effects of a project by performing positive actions elsewhere; yet that is only one aspect of mitigation. Internationally, the Business and Biodiversity Offsets Programme recognizes a "mitigation hierarchy" that includes avoidance, minimization, rehabilitation/restoration, and offset (http://bbop.forest-trends.org/pages/mitigation_hierarchy). This hierarchy is mirrored in similar terms in environmental assessment mitigation and offset policies around the world. Regulation in the US defines mitigation as being inclusive of minimizing project impacts (US Code of Federal Regulations, Title 40, Chapter V, Part I508, Section I508.20, "Mitigation"). Under these regulations, translocations primarily serve as minimization (presumed reductions in the number of deaths that will occur as a direct result of the project). Without additional regulatory requirements to monitor the fate of translocated individuals, to design studies that improve translocation strategies for future attempts, and to ensure that relocated individuals contribute to the establishment of viable populations at the receiving site, the regulatory intent of mitigating population-level detrimental effects is little more than wishful thinking. 


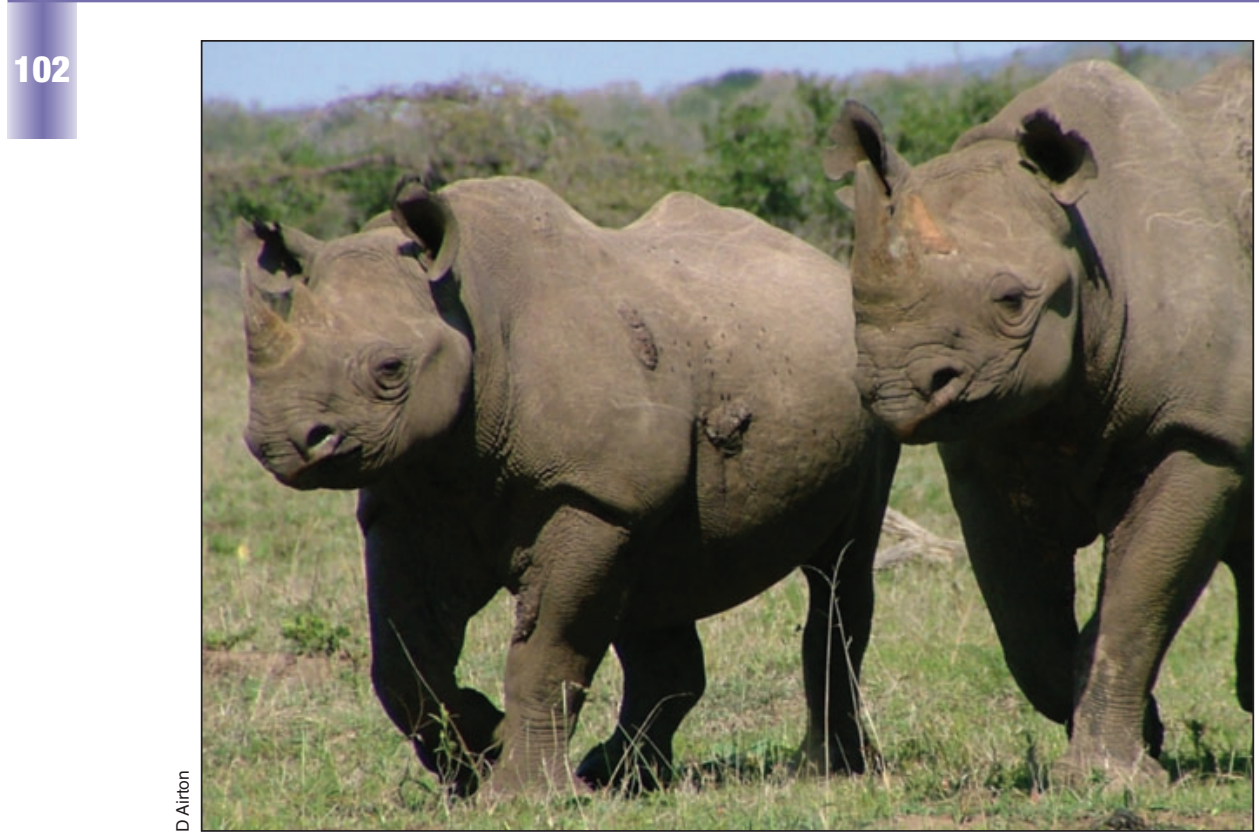

Figure 2. Black rhinoceros (Diceros bicornis) populations have benefited greatly from metapopulation management through translocation. Excellent record-keeping by government biologists and private partners has enabled the resulting data to be analyzed and applied for management.

\section{Global lack of documentation}

The outcomes of mitigation-driven translocations are often poorly documented. Despite the large numbers of animals translocated from the pathway of development, little attention is paid to whether the numbers removed represent a substantial proportion of the animals actually present at the site, or whether the translocated individuals survive to establish or augment a viable population at the release site. These issues can be particularly problematic for species that are hard to detect. In the UK, for example, one study involving a cryptic species of lizard (the slow worm A fragilis) showed that the removal of more than 100 individuals did not substantially deplete the population (Platenberg and Griffiths 1999). Claims that considerable numbers of animals can be removed from sites over the course of a few days or weeks seem untenable in many cases, and may reflect issues with detectability rather than actual numerical declines.

A wider understanding of mitigation-driven translocations is currently hindered by limited access to data. Even in wealthy nations such as Australia, the UK, and the US, record-keeping for mitigation-driven translocations is almost always inadequate, inaccessible, or nearly nonexistent. In Australia, state-based governance of development proposals discourages the creation of a national registry of approved developments and their conditions of consent (to development). State-based registries keep records of only the largest approved developments, and there is no example in Australia of a systematic registry that records the details of translocations that occur in a mitigation context. In the UK, the quantity and accessibility of records depends on the protection afforded to the species. For highly protected species, there is a legal requirement to submit a report to the relevant government agency. However, enforcement of this requirement has been limited; one-half of the case studies on file lack any type of report (Edgar et al. 2005; Lewis 2012). When reports are submitted, less than $10 \%$ contain informative population monitoring data (Lewis 2012). Although the US Fish and Wildlife Service (USFWS) issues permits for mitigationbased translocations of species protected under the US Endangered Species Act, there is no comprehensive system to track results. Furthermore, very few US statebased agencies monitor this issue, and in the rare cases when such translocations are tracked, it is often for only one or two key species (eg the Florida Fish and Wildlife Conservation Commission monitoring of gopher tortoise translocations).

Determining the effectiveness of mitigation-based translocations is often complicated by the absence of governmental tracking and monitoring. Moreover, the failure of developed nations to implement best practices for documenting translocations means that there are no model systems to emulate. The United Arab Emirates, for example, is currently experiencing extremely rapid development and is requiring translocations of flora and fauna for mitigation (Gardner and Howarth 2009), but the country's natural resource managers lack templates to follow. The utility of good record-keeping systems lies not only in documenting whether translocations are working properly, but also in evaluating the conditions and methodologies under which success is optimized. For instance, detailed record-keeping on black rhinoceros (Diceros bicornis; Figure 2) translocations by the South African governmental agencies administering a conservationdriven translocation program enabled a large, retrospective meta-analysis that identified key ecological and management factors predicting success (Linklater et al. 2011, 2012).

\section{Poor implementation}

The success rate of scientifically responsible translocations, outside the mitigation context, is approximately 26-46\% (Griffith et al. 1989; Linnell et al. 1997; Germano and Bishop 2009), depending on the definition of success and the taxonomic group involved. Data for mitigation-based translocations may not exist or are difficult to obtain, either because post-release monitoring was not required or because the data are "buried" in largely inaccessible reports to regulatory agencies (but see Platenberg and Griffiths 1999; Esque et al. 2010). Yet in some cases conservation practitioners have been able to 
access such data, thereby providing insights into possible success rates for this underreported class of translocations.

On the west coast of New Zealand, thousands of endangered carnivorous land snails were translocated at a cost of over NZ\$2 million (US\$1.56 million) in order to make way for an opencast coal mine (TerraNature 2006). While monitoring occurred during the first 18 months, the death rate of tracked snails was 30\%; population models suggested that such high mortality rates would cause population collapses for this long-lived and slow-to-breed species (Morris 2010). In California, populations of several species of kangaroo rats (Dipodomys spp), involving thousands of individuals, have been relocated through mitigation-driven translocations, but until recently, most of these efforts were unsuccessful, with no individuals surviving after 1 year post-release (Shier and Swaisgood 2012). By contrast, a scientifically based translocation program, sensitive to the ecological and behavioral requirements of the species, has yielded high survival and reproductive rates and the establishment of five new populations (Shier and Swaisgood 2012). This study raised an issue that was not immediately evident to wildlife managers: namely that translocating members of solitary, aggressive species alongside familiar neighbors affects establishment and postrelease fitness. Without clear empirical evidence from carefully designed experiments, this knowledge would not have found its way into management strategies for the species. Other examples of poor translocation outcomes abound, albeit without scientific conservation-driven counterparts for comparison (Panel 2).

A parallel approach to mitigation-driven translocations may be found in the welfare-motivated relocations of nuisance wildlife, which also benefit little from the latest scientific innovations in conservation-driven translocations. Although rarely documented, what studies are available typically exhibit poor success rates (Massei et al. 2010), with mortality rates as high as $97 \%$ for gray squirrels (Sciurus carolinensis; Adams et al. 2004). By contrast, Frair et al. (2007) took an experimental approach to translocating North American elk (Cervus elaphus) from areas with high levels of human-animal conflict and releasing them into areas where the elk would have conservation value, thereby avoiding the need for lethal control. In a carefully designed experiment conducted in partnership with regional governmental agencies in Canada, these authors demonstrated empirically that, somewhat unexpectedly, releasing elk into high-quality foraging areas was associated with lower survival due to increased predation. This study again underscores the important role of experimentation in translocation biology. Mitigation-driven translocations represent an excellent opportunity to test hypotheses and, over time, devise optimal protocols based on clear empirical evidence. Unfortunately, this opportunity for improving knowledge is rarely taken.

The flaws in mitigation-driven translocations cannot

\section{Panel 2. Case studies of mitigation-driven translocations}

Mitigation-driven translocations are affecting a wide range of taxonomic groups worldwide (Figure 3). Although most cases lack adequate monitoring and reporting, the large and growing number of development projects should require scientists, managers, and policy makers to assess the use of this tool and its impacts on the wildlife it is meant to protect.

(a) Burrowing owls (Athene cunicularia) are routinely subjected to "passive relocation" in North America, where the birds are evicted from their burrows as a form of mitigation to remove them from harm's way before the land clearing begins. Although consultants are often paid lucrative fees to perform the relocation, post-release monitoring is rarely considered. It is therefore not known whether eviction ultimately leads to the same fate as being killed on site, or what effects the relocated owls might have on the social dynamics of individuals already residing at the site where they settle.

(b) In the UK, the great crested newt (Triturus cristatus) is frequently found at development sites, resulting in the licensing of hundreds of mitigation projects each year. Although millions of pounds sterling are spent on great crested newt mitigation in the UK, it is unclear whether the actions undertaken have been effective (Lewis 20I2).

(c) Due to coal mining on public lands on New Zealand's west coast, over 6500 individuals of two species of large endemic and endangered land snails (Powelliphanta spp) have been translocated over the past 10 years (Morris 2010). Several of the translocated populations have already failed. More than $\mathbf{8 0 0}$ of these snails died while temporarily taken into captivity (TerraNature 2006).

(d) In the US, several mitigation-driven translocations of the endangered Stephens' kangaroo rat (Dipodomys stephensi) resulted in $100 \%$ mortality, while a science-based translocation program developed by testing behavioral and ecological hypotheses succeeded in establishing several reproducing populations (Shier and Swaisgood 20I2)
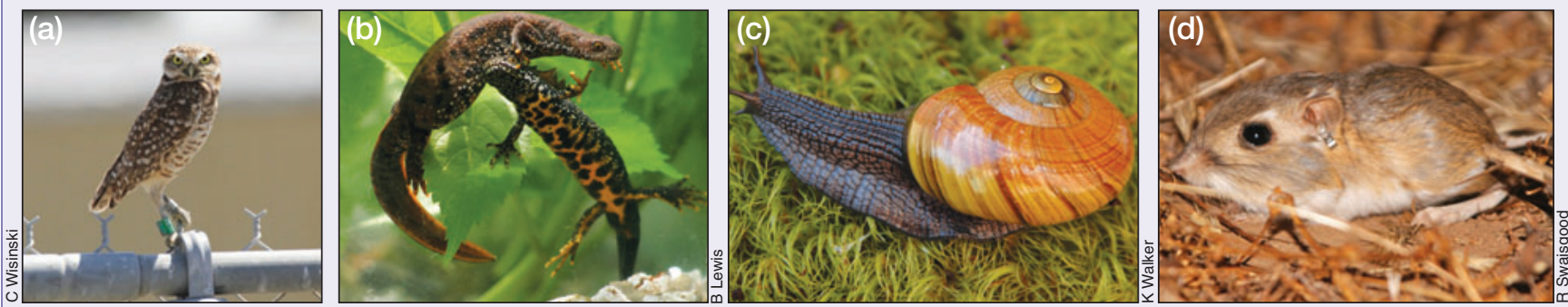

Figure 3. Examples of species affected by mitigation translocations: (a) burrowing owl (Athene cunicularia); (b) great crested newt (Triturus cristatus); (c) land snails (Powelliphanta); (d) Stephens' kangaroo rat (Dipodomys stephensi). 
be assigned solely to poor scientific preparation, as these initiatives are subject to constraints that are absent in conservation-driven translocations. For instance, the timing of the required actions is often driven by the developer's schedule, rather than by a sound ecological assessment of the length of time necessary to remove a population and re-establish it elsewhere. This is particularly problematic for habitat-limited but widespread species, where lack of suitable unoccupied sites within the species' range led to releases into occupied habitat with unknown consequences for the resident and receiving populations.

\section{A misguided conservation strategy}

While government agencies largely fail to document mitigation-driven translocations, the scientific community has likewise failed to raise this as a concern. Indeed, such activities are essentially ignored by the scientific community (though see Richard-Hansen et al. 2000; Edgar et al. 2005; Kyek et al. 2007; Esque et al. 2010; IUCN/SSC 2013). In a textbook on reintroduction biology, Seddon et al. (2012) outlined reasons for translocations; although several types of wildlife translocations - including conservation-driven efforts - were described in detail, there was little mention of mitigation-driven translocations. Meanwhile, the relative success of scientific conservation-driven translocations is being used to justify the use of mitigation-driven translocations globally.

Mitigation translocations often represent a misguided conservation strategy. In 1983, scientists warned that while translocating red-cockaded woodpeckers (Picoides borealis) from development sites in the southeastern US might be possible, it should not be considered as a simple or appropriate mitigation strategy (Jackson et al. 1983). Three decades later, the same concerns and considerations are still relevant, but are ignored by the majority of the conservation community and the involved regulatory agencies. Mitigation-driven translocations are, by our definition, supply driven, meaning that they are initiated in response to a supply of animals that must be removed from harm's way. Conservation translocations are demand driven, being implemented to establish viable populations in suitable unoccupied or under-occupied habitat with the aim of conserving the species. By contrast, the majority of mitigation-driven translocations serve no conservation purpose, despite regulatory intent. The current "tit-fortat" approach - requiring direct alleviation of impacts specifically linked to the animals and plants at the affected site - virtually ensures a piecemeal, ad hoc approach to species conservation. Other goals for species recovery may then go unaddressed and unfunded, and the project may be unjustifiable as a conservation tool even if the translocated individuals survive. Indeed, translocations may do more harm than good if release sites are not carefully chosen. If animals are released into areas already near their ecological carrying capacity, then the survival of released animals may come at the cost of higher mortality among members of the resident population, potentially exacerbated by social disruption or disease transmission (Aiello et al. 2014). If survival and establishment are low, as we suspect is the case for many species, then translocation will have negligible conservation value, despite a suitable release site having been selected.

We contend that there is a large gap between the regulatory intent of mitigation-driven translocations and their implementation: moving individual animals away from a development site without addressing the bigger conservation picture. Part of the problem is conceptual: how does one define and assign metrics to "success" in such projects (Miller et al. 2014)? Establishment of a viable population from the relocated founders is not usually the primary goal of mitigation-driven releases, although it is the implied regulatory or legislative intent (Panel 1). However, there have been many failures to meet even the less lofty aim of ensuring survival of animals in the short term. Regrettably, most current regulatory regimes aim to protect individuals but fail to conserve populations, and therefore do neither.

Endangered species conservation has long been underfunded; only US\$176 million was allocated to endangered species in the USFWS's 2012 budget (Corn 2012). More conservation dollars are not likely to be forthcoming, and it is imperative to use what little there is more wisely. Mitigation-driven translocations, funded by developers rather than taxpayers, should conform to best-practice standards for conservation science. It should be the responsibility of the developers, their consultants, and the regulatory agencies to demonstrate the effectiveness of translocation as a tool to achieve conservation outcomes that are consistent with the regulatory intent. This process should be transparent, with clear goals for each translocation and data made freely available for public scrutiny. If current regulations and practices do not uphold these standards, they should be revised. When translocation as a tool is ill-suited to offsetting the impacts of a planned development on a protected species, then the regulatory framework should be flexible enough to allow other, more strategic approaches, regardless of whether they entail the loss of some individuals. Under these circumstances, better use of development mitigation dollars can be realized if applied to achieve range-wide strategic conservation priorities for the affected species.

\section{Acknowledgements}

Data on translocations occurring in the state of Florida were obtained from the Florida Fish and Wildlife Conservation Commission with the help of S Power and J Berish. We thank R Averill-Murray, M Pavelka, B Lewis, L Barea, and J Perry for assistance with and comments on this manuscript, the findings and conclusions of which are those of the authors and do not necessarily represent the views of their affiliated organizations. 


\section{References}

Adams LW, Hadidian J, and Flyger V. 2004. Movement and mortality of translocated urban-suburban grey squirrels. Anim Welfare 13: 45-50.

Aiello CM, Nussear KE, Walde AD, et al. 2014. Disease dynamics during wildlife translocations: disruptions to the host population and potential consequences for transmission in desert tortoise contact networks. Anim Conserv 17(S1): 27-39.

Corn ML. 2012. Fish and Wildlife Service: FY2013 appropriations and policy. Congressional Research Service Report R42466.

Desmond J. 2012. Ivanpah and the DOE loan guarantee program. Bright Source Energy. www.brightsourceenergy.com/ivanpahand-the-doe-loan-guarantee-program\#.UytlovldU61. Viewed 6 May 2014.

Edgar PW, Griffiths RA, and Foster JP. 2005. Evaluation of translocation as a tool for mitigating development threats to great crested newts (Triturus cristatus) in England, 1990-2001. Biol Conserv 122: 45-52.

Esque TC, Nussear KE, Drake KK, et al. 2010. Effects of subsidized predators, resource variability, and human population density on desert tortoise populations in the Mojave Desert, USA. Endang Species Res 12: 167-77.

Frair JL, Merrill EH, Allen JR, and Boyce MS. 2007. Know thy enemy: experience affects elk translocation success in risky landscapes. J Wildlife Manage 71: 541-54.

Gardner AS and Howarth B. 2009. Urbanisation in the United Arab Emirates: the challenges for ecological mitigation in a rapidly developing country. BioRisk 3: 27-38.

Germano JM and Bishop PJ. 2009. Suitability of amphibians and reptiles for translocation. Conserv Biol 23: 7-15.

Griffith B, Scott JM, Carpenter JW, and Reed C. 1989. Translocation as a species conservation tool: status and strategy. Science 245: 477-80.

Hill D and Arnold R. 2012. Building the evidence base for ecological impact assessment and mitigation. J Appl Ecol 49: 6-9.

Hoegh-Guldberg O, Hughes L, McIntyre S, et al. 2008. Assisted colonization and rapid climate change. Science 321: 345-46.

IUCN/SSC (International Union for Conservation of Nature/Species Survival Commission). 2013. Guidelines for reintroductions and other conservation translocations. Version 1.0. Gland, Switzerland: IUCN/SSC.

Jackson JA, Schardien BJ, and Miller PR. 1983. Moving red-cockaded woodpecker colonies: relocation or phased destruction? Wildlife Soc B 11: 59-62.

Kyek M, Maletzky A, and Achleitner S. 2007. Large scale translocation and habitat compensation of amphibian and reptile populations in the course of the redevelopment of a waste disposal site. Z Feldherpetologie 14: 175-90.

Leggett D. 2011. Environmental management and monitoring of dredging and reclamation. Dredging International. www.ciria. com/emsagg/Seminar_London_Gateway.htm. Viewed 19 Aug 2014.

Lewis B. 2012. An evaluation of mitigation actions for great crested newts at development sites ( $\mathrm{PhD}$ dissertation). Canterbury, UK: University of Kent.

Linklater WL, Adcock K, Du Preeze P, et al. 2011. Guidelines for large herbivore translocation simplified: black rhinoceros case study. J Appl Ecol 48: 493-502.

Linklater WL, Gedir JV, Law PR, et al. 2012. Translocations as experiments in the ecological resilience of an asocial megaherbivore. PLoS ONE 7: e30664.

Linnell JD, Aanes R, Swenson JE, et al. 1997. Translocation of carnivores as a method for managing problem animals: a review. Biodivers Conserv 6: 1245-57.

Massei G, Quy RJ, Gurney J, and Cowan DP. 2010. Can translocations be used to mitigate human-wildlife conflicts? Wildlife Res 37: 428-39.

McFadden M, Duffy S, Harlow P, et al. 2008. A review of the green and golden bell frog Litoria aurea breeding program at Taronga Zoo. Aus Zool 34: 291-96.

Miller KA, Bell T, and Germano JM. 2014. Understanding publication bias in reintroduction biology by assessing translocations of New Zealand's herpetofauna. Conserv Biol 28: 1045-56.

Morris R. 2010. An unfortunate experiment. Forest and Bird 337: $14-18$.

Platenberg RJ and Griffiths RA. 1999. Translocation of slowworms (Anguis fragilis) as a mitigation strategy: a case study from south-east England. Biol Conserv 90: 125-32.

Richard-Hansen C, Vie J-C, and de Thoisy B. 2000. Translocation of red howler monkeys (Alouatta seniculus) in French Guiana. Biol Conserv 93: 247-53.

Seddon PJ, Armstrong DP, and Maloney RF. 2007. Developing the science of reintroduction biology. Conserv Biol 21: 303-12.

Seddon PJ, Strauss WM, and Innes J. 2012. Animal translocations: what are they and why do we do them? In: Ewen JG, Armstrong DP, Parker KA, et al. (Eds). Reintroduction biology: integrating science and management. West Sussex, UK: WileyBlackwell.

Shier DM and Swaisgood RR. 2012. Fitness costs of neighborhood disruption in translocations of a solitary mammal. Conserv Biol 26: 116-23.

Teixeira CP, de Azevedo CS, Mendel M, et al. 2007. Revisiting translocation and reintroduction programmes: the importance of considering stress. Anim Behav 73: 1-13.

TerraNature. 2006. High risk of extinction from Powelliphanta snail translocation. www.terranature.org/snailTranslocation.htm. Viewed 6 May 2014.

Williams CE. 2011. From Shell Haven to Wiltshire - notes on the UK's biggest mass reptile translocation. ARG Today 9: 2-4.

\section{TAKE THIS JOURNAL TO YOUR LIBRARIAN, PLEASE}

Are you enjoying this issue of Frontiers?

If your library had a subscription, colleagues and students could enjoy it too. Please consider recommending Frontiers in Ecology and the Environment to your library.

of Clip or copy the form below. Thank you for your support.

Library Recommendation Form

To Acquisition Librarian, Serials

From

Dept

Signature

Date

I recommend the library subscribe to: Frontiers in Ecology and the Environment (ISSN 1540-9295)

To request a free sample issue of Frontiers in Ecology and the Environment, email Eric Gordon at eric@esa.org.

Order Frontiers by contacting ESA Headquarters at (202) 833-8773, online at www.esa.org, or through your subscription agent. 